\title{
SIGNIFICANCE OF THE HISTORY OF MATHEMATICS TO THE TEACHER OF ELEMENTARY MATHEMATICS. ${ }^{1}$
}

\author{
By Alva Walker Stamper, Ph.D., \\ State Normal School, Chico, Cal.
}

One way for the teacher of elementary mathematics better to direct the powers and understand the capabilities of his pupils, is to learn first something of the tendencies and difficulties of the race in its mathematical development. It is not to be expected that the pupil will or should repeat all the errors of commission and omission made by his remote ancestors nor that he follow the devious paths which led them to mathematical truths; but a review of the history of mathematics and of its teaching shows certain well marked correspondences between the development of the race and of the individual. Hence, a knowledge on the part of the teacher of the historical development of the subject matter of mathematics and of racial tendencies and difficulties in this development should give a good perspective for present teaching.

Mathematics had a practical beginning. Nations counted and made computations without and with symbols before the science of numbers (the arithmetica of the Greeks) was undertaken. Algebra was largely an outgrowth of the arithmetical problem. The logical geometry of the Greeks was preceded by the practical work in mensuration and surveying of the Egyptians and there is good reason for believing that the Greeks were stimulated in their efforts to organize the science of geometry by their interest in astronomy. There is small wonder that it is being realized to-day that pupils of both the elementary and the secondary school should get their start in mathematics through work that is essentially practical to them.

The tendency to hold to the special is noticed in the mathematical development of the race. In their use of fractions the Egyptians employed those with numerator I, the Babylonians with denominator 60 , and the Romans with denominator I2. These nations probably made less progress in their study of fractions than if they had handled freely the general fraction. The tendency to hold to the special has been marked in the history of algebra. The early Greeks, for example, solved separately by geometric means the several forms of the quadratic equation. It was approximately $\mathrm{r}, 000$ years before the general form of the

'Read before the Mathematics Section of the California Teachers' Association, Decentber 29. 1910 . 
quadratic was recognized and used by the Hindus. In the early development of geometry separate proofs were often given by the Greeks for the various kinds of figures of a certain class, in which there was no logical or pedagogical gain. Since the race was relatively slow in reaching a conception of the general, it is well to consider in teaching the probable difficulties of the pupil in this connection.

Teachers shotld not be surprised that pupils tend to assume much in attempting the proofs of mathematical propositions. Euclid, himself, was not blameless in this regard and neither were less prominent writers of from 1,500 to 2,000 years later. Some of our recent texts in geometry are following historic precedent (and wisely so) in assuming the truths of certain early self-evident propositions.

The high-school teacher should not be discouraged if pupils find difficulty in understanding the symbolic language of mathematics. The race did not readily adopt a comprehensive number symbolism. The symbolic form of the equation was the result of a slow development and the recognition of negative roots of an equation was delayed centuries after the solution of quadratics had been begun.

Some topics in mathematics have not always been easily or satisfactorily handled. The study of the incommensurable, for example, has apparently always given difficulty, as shown in the history of the teaching of geometry. Euclid recognized the unsatisfactory treatment of incommensurables in relation to the theory of limits, and substituted a treatment of ratio and proportion whose definitions eliminated these difficulties. Later texts abandoned Euclid's treatment of proportion for the algebraic method, notably books printed on the continent and intended for use in higher secondary schools. These texts, some of which appeared as early as the seventeenth century, generally ignored the incommensurable case.

While it is fair to assume that certain tendencies of the race are to a great extent duplicated in the mathematical development of the individual, it is taking too much for granted to suppose that the mathematical development of the individual should necessarily follow the lines of development of the race. Thus, because the race found out comparatively late the value of the decimal fraction, the pupil of the elementary school should not be required to wait until after he has studied all of common fractions before he is allowed the valuable aid of decimals in com- 
putation. Again, while the race worked algebraic problems long before the fundamental operations of algebra were fully developed, pupils should not be expected to work more than a few very simple problems before they learn the language and the simple processes of algebra. It appears that some of our present texts are introducing too difficult problems for the introductory work in algebra. Again, while the notion of function was a late but most fundamental development in the history of algebra, the opportunity to grasp an elementary idea of function should not be lost in elementary algebra; such as is offered through the use of the graph. The writer does not believe, however, that the elementary course in algebra should be merely an introductory course to the theory of functions.

Besides knowing the history of mathematics in order to understand the tendencies and difficulties of the race in its mathematical development and to appreciate better possible similar traits in the pupil's mathematical development, the teacher should know the history of mathematics also for the sake of understanding the development of its subject matter. Such a study will often throw light on the logical structure of certain phases of this subject matter. For example, the teacher of geometry who knows of the study of parallels from the time of the early Greeks to the present, who knows of the necessity of Euclid's assumption, who knows of the later attempts to prove the parallel axiom, and who knows something of the development of non-Euclidean geometry, is in a position of authority when treating the subject of parallels. With this historical perspective the teacher will know why a student should not expect to prove the parallel axiom. Again, a teacher who has read the history of the three famous problems of antiquity is fortified against the importunities of the circle squarer, the angle trisecter, and the cube duplicater.

The high-school student is concerned only in an indirect way with the history of mathematics. The teacher may often stimulate a class in arithmetic, algebra, or geometry by relating an historic fact immediately related to the work in hand. Thus, in geometry by referring to the methods of the rope fasteners or to the probable origin of the recognition of the truth of the Pythagorean theorem; or in algebra, to a method used by the Hindus in solving quadratic equations; or in arithmetic, to some early number symbols or methods of multiplying or dividing. The practicing teacher is right in contending that there is no time for frills and fancies in teaching mathematics, where much drill is nec- 
essary to bring aboit a fair degree of proficiency on the part of the pupils; but if the teacher keeps alive his own interest in the history of mathematics he can often find opportunity to give his class incentives to do harder and better work.

\section{INDUSTRY IN THE LEADING COPPER PRODUCING STATES.}

\section{ARIZONA.}

For 1910 Arizona again takes the lead among the copper producing states with an output slightly above the production of 1909 , which was $291,110,29 \mathrm{~s}$ pounds. The Bisbee district was the largest producer, with an output of approximately $145,000,000$ pounds, as compared with about $130,000,000$ pounds for 1909 .

\section{MONTANA.}

The copper production of Montana will probably not exceed 285,000,000 pounds for 1910 , as compared with $314,858,291$ pounds for 1909 . The state will therefore rank second to Arizona as a copper producer.

\section{MICHIGAN.}

Michigan, ranking third as a copper producing state, made an output of refined copper of about $220,000,000$ pounds in 1910 , as compared with $227,005,923$ pounds for 1909 .

UTAH.

Utah, ranking fourth among the copper producing states, made a marked increase in production over that for 1909 , which was $101,241,114$ pounds. The production was mainly from the Bingham district.

\section{NEVADA.}

The production of copper in Nevada for 1910 was about $64,000,000$ pounds, as compared with $53,849,281$ pounds for 1909 . The output was mainly from the Ely district, the ores coming entirely from the Copper Flat pit.

\section{CALIFORNIA.}

The output of copper from California will show a considerable decrease in 1910 from the output of $53,568,708$ pounds produced in 1909 . The decrease is due to the necessity of controlling the smelter fumes in the Shasta County district.

\section{TENNESSEE}

Tennessee will also show a decrease for 1910 from the output of $19,207,745$ pounds for 1909 . This decrease is due to the fact that the sulphuric acid plants operated by both companies in the Ducktown district were not able to handie the fumes produced by the smelting plants when they are operated at full capacity.

\section{CHICAGO TEACHERS EXAMINATION.}

The Board of Education of Chicago will hold an examination June 26 anc 27,1911 , for teachers in high schools, the following majors only: Spanish, Polish, zoölogy, physiology and sanitation, physics, chemistry, mathematics: accounting, foundry, blacksmithing, electrical construction, mechanical draw. ing, physiography, phonography, commercial geography, and physical educa. ticn. Write the Board's examiners for information. 